\section{University of New Hampshire}

Carsey School of Public Policy

\section{CARSEY RESEARCH}

National Fact Sheet \#34

Summer 2016

\title{
U.S. Births Remain Low as the Great Recession Wanes More Than Three Million Fewer Births and Still Counting
}

Kenneth M. Johnson

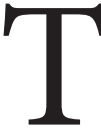

The Great Recession sent an economic shock through American society that reached far beyond the stock and housing markets. More than five years after economists announced the end of the recession, fertility levels have still not recovered. As a result, more than 3.4 million fewer babies were born in the United States between 2008 and 2015 than would have been expected if pre-recession fertility rates had been sustained (see Figure 1). In each of the last five years, this birth deficit has resulted in roughly 500,000 fewer births.

\section{FIGURE 1. ACTUAL BIRTHS COMPARED TO BIRTHS USING 2007 BIRTH RATES, 2008 TO 2015}

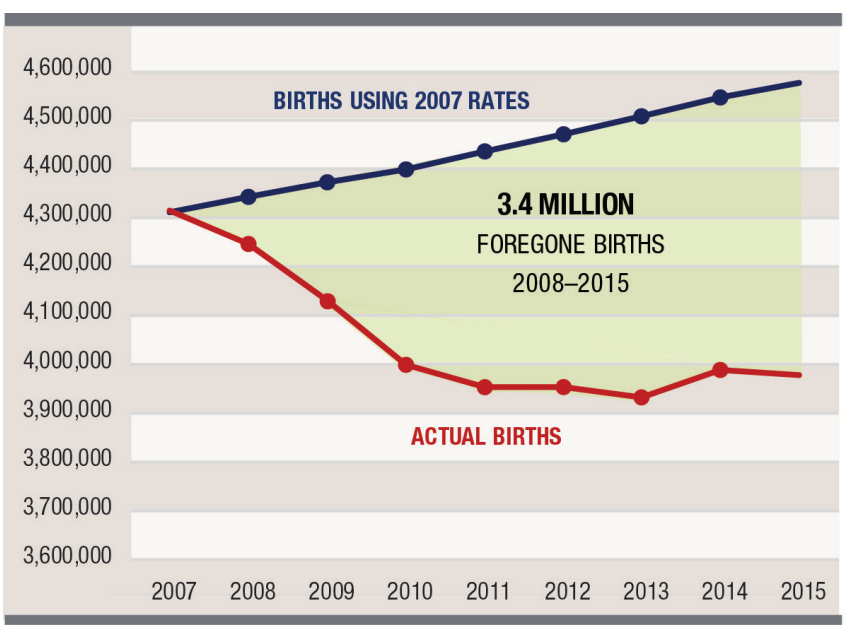

Analysis: K.M. Johnson, Carsey School, University of New Hampshire Source: National Center for Health Statistics

Nor do new data just released show any evidence of an upturn in births. National Center for Health Statistics data for 2015 show the lowest general fertility rate on record and only 3,978,000 births last year. There were 338,000 (8 percent) fewer births in 2015 than in 2007, just before the Recession began to influence fertility. This decline in

\section{KEY FINDINGS \\ $3.4 \mathrm{M}$ \\ Since the onset of the Great Recession, there have been 3.4 million fewer U.S. births than expected. \\ 600,000 In 2015, the shortfall of births was nearly 600,000 \\ Births diminished despite more women of childbearing age. \\ Recent data provide no evidence of any upturn in birth rates.}

births is entirely due to reduced fertility rates. The number of women in their prime childbearing years (20 to 39) actually increased by 2.5 million ( 6 percent) between 2007 and 2015. With more women of child-bearing age, the expectation would be for more babies. Yet the larger cohort of childbearing age women in 2015 produced fewer births than the smaller 2007 cohort did. If the fertility rates of 2007 had been sustained through 2015, the larger cohort of women of childbearing age would have been expected to produce nearly 600,000 more children in 2015 than were actually born.

The recession and its aftermath had a particularly pronounced impact on the fertility of younger women. For example, women 20 to 29 had 468,000 (19 percent) fewer babies in 2015 than would have been expected had the fertility levels of 2007 been sustained (see Figure 2). This sharp reduction in births was due to lower fertility rates among this age group. There were actually $1,624,000$ (8 percent) more women who were 20 to 29 in 2015 than there were in 2007 . The fertility rate decline was greater for women 20 to 24 (-27 percent), but it was substantial 


\section{FIGURE 2. MANY FEWER BIRTHS THAN EXPECTED FOR YOUNG WOMEN AND SLIGHTLY MORE BIRTHS FOR OLDER WOMEN, 2015}

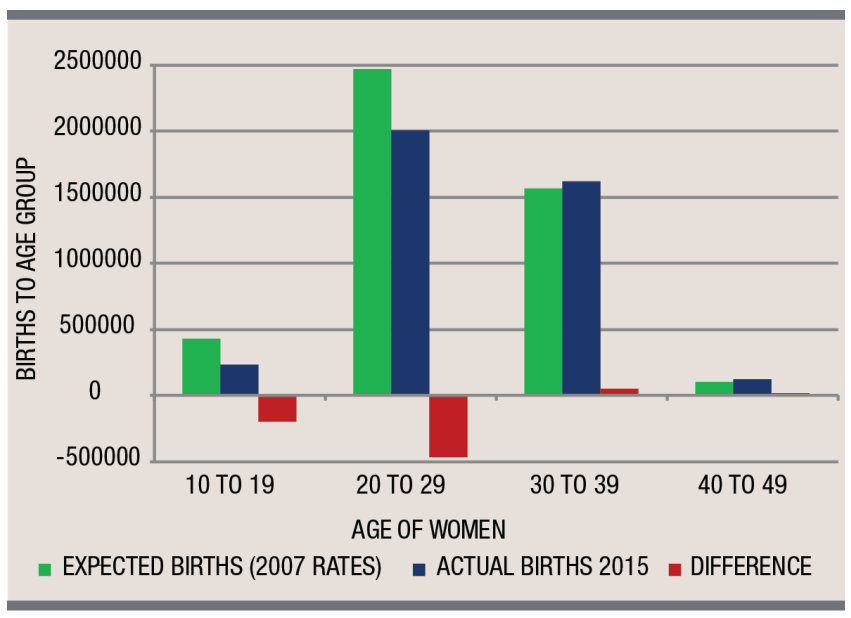

Analysis: K.M. Johnson, Carsey School, University of New Hampshire Source: National Center for Health Statistics

for women 25 to 29 (-12 percent) as well. Fertility rates for women in their 20s declined for all racial groups, but the decline was greatest for young Hispanic women. An even greater fertility decline (-46 percent) occurred to women 10 to 19 . Though this age group has far fewer births than those in their 20s, the substantial fertility rate decline among these very young women resulted in 197,000 fewer births in 2015 than would have been expected had 2007 fertility rates prevailed. Because teenage mothers and their babies face significant health, economic, and social challenges, this decline in teen births between 2007 and 2015 is considered a positive change.

Fertility rates among women 30 to 39 actually increased slightly ( 3 percent) between 2007 and 2015. This is in sharp contrast to the substantial fertility rate declines among younger women. There were nearly 5 percent more 30 to 39 year old women in 2015 than in 2007, so more births to this group would be expected-but slightly higher fertility rates produced an additional 50,000 more births than expected among this age group. Fertility rates increased slightly for women 30 to 39 among all racial groups, except Hispanics.

Economic recessions often temporarily reduce fertility both because there are fewer young, high fertility immigrants and because families and individuals under economic stress struggle to balance their work and family responsibilities. Women often postpone marriage and childbearing in such uncertain times. This is a particularly viable option for young women because they have long fertility horizons. Older women have less opportunity to delay. A critical question right now is: have women just delayed births because of the Great Recession and its aftermath, or will they forego these births entirely? There is currently no clear answer to this question. Women who were
20 to 29 in 2008 are now 27 to 36 . If they just delayed children, we would expect a significant rise in fertility rates for those in their late 20s and 30s soon. There is no evidence of this in the recently released NCHS data. The modest increase in fertility rates among women in their 30 s to date is insufficient to make up the 3.4 million birth shortfall. Birth rates must rise substantially and soon to make up a significant proportion of this birth dearth.

The United States has not experienced an economic displacement of the magnitude of the recent recession in two generations. The Great Depression of the 1930s also had a substantial and lasting impact on U.S. fertility. Young women who entered their childbearing years early in the Depression also delayed having children. The net result for them was extremely low lifetime fertility and the highest level of childlessness ever recorded. In essence, they never fully recovered from delaying their fertility during the Depression. It is too early to determine yet what implications this recession will have for long term U.S. fertility. But whether they are just delayed or foregone, the 3.4 million missing births so far mean there are currently many empty beds in maternity wards, less business for firms in the baby industry, and many empty seats in kindergarten classrooms.

\section{Data}

Fertility rates are calculated by dividing the number of births to mothers in a given age group by the total number of women in that age group. To estimate the impact of the recession on births, newly released birth data for 2015 from the National Center for Health Statistics (NCHS) were merged with historical NCHS birth data and combined with Census Bureau annual estimates of the female population of childbearing age. Pre-recessionary fertility was estimated by multiplying 2007 age-specific fertility rates for women 15 to 49 by the actual number of women in each five year age cohort for each year from 2008 to 2015. These expected births were then compared to the actual births in that year reported by NCHS. The difference between the two estimates the effect of the recession and its aftermath on births.

\section{About the Author}

Kenneth M. Johnson is senior demographer at the Carsey School of Public Policy and professor of sociology at the University of New Hampshire (ken.johnson@unh.edu).

\section{A ck now led g ments}

The author thanks Michael Ettlinger, Amy Sterndale, Curt Grimm, Michele Dillon, Bianca Nicolosi, and Laurel Lloyd at the Carsey School of Public Policy at the University of New Hampshire for their comments and suggestions. 